\title{
Competition in health care: lessons from the English experience
}

\author{
CAROL PROPPER* \\ Imperial College London, London, UK
}

\begin{abstract}
The use of competition and the associated increase in choice in health care is a popular reform model, adopted by many governments across the world. Yet it is also a hotly contested model, with opponents seeing it, at best, as a diversion of energy or a luxury and, at worst, as leading to health care inequality and waste. This paper subjects the use of competition in health care to scrutiny. It begins by examining the theoretical case and then argues that only by looking at evidence can we understand what works and when. The body of the paper examines the evidence for England. For 25 years the United Kingdom has been subject to a series of policy changes which exogenously introduced and then downplayed the use of competition in health care. This makes England a very useful test bed. The paper presents the UK reforms and then discusses the evidence of their impact, examining changes in outcomes, including quality, productivity and the effect on the distribution of health care resources across socioeconomic groups. The final section reflects on what can be learnt from these findings.
\end{abstract}

Submitted 1 April 2017; revised 19 May 2017; accepted 1 July 2017;

first published online 8 February 2018

\section{Introduction}

The health care sector is characterised by expenditure growth over a long period, driven by a combination of population change and income growth on the demand side and innovation on the supply side. The ensuing rise in spending has meant that raising quality whilst keeping costs under control is a central issue for policy makers. The introduction of competition into health care has been seen as one means of tackling this issue.

Competition in health care has a simple political appeal. In the rest of the economy, competition is generally argued to promote growth (e.g. Aghion et al., 2005 ) and its introduction into traditionally heavily regulated and often centrally delivered and financed health care systems is argued to increase consumer responsiveness and drive quality and productivity increases (Le Grand, 2006).

\footnotetext{
*Correspondence to: Carol Propper, Imperial College London, London SW7 2AZ, UK. Email: propper@ imperial.ac.uk
} 
However, competition in the largest health care market in the world - the United States - has been accompanied by a wave of consolidations on both the insurer and delivery sides of the market, leading to price increases for consumers and mixed effects on quality (e.g. Gowrisankaran et al., 2015). This has led to questions about the functioning of markets in health care and the use of competition as a tool.

This paper examines the lessons that can be learnt from the use of competition in the regulated and more publicly funded European context, in which universal coverage is in place and the commitment to equity is strong. The paper focuses on the United Kingdom and within this, mainly England. In the European context, the United Kingdom has been a pioneer in opening up previously heavily regulated and centralised public services to competition. Following a wave of privatisations of utilities and transport systems in the 1980s, the UK government turned its attention to public services, opening up education, housing and health care to competition in the provision of services (Le Grand and Bartlett, 1993). This paper examines what can be learnt from the UK experience in using competition and the associated change in consumer choice in hospital services to improve health care outcomes.

The review primarily marshals evidence which is derived from primarily from administrative data and within that evidence that employs research designs that attempt to control for other policy changes that occurred alongside the pro-competitive reforms. Much of the evidence on the behaviour of health care providers adopts a reduced form approach in which the change in behaviour of health care providers most affected by the reforms is compared to the change in behaviour of those less affected. To limit contamination from other policy changes, most of these analyses compare periods that are close in time before and after the reforms. There is also a slowly growing body of evidence that employs structural analysis, particularly that which focuses on the choices made by users of care. Few of the studies provide a full welfare analysis of these policies: instead they examine whether and how providers and users of health care responded to the change in incentives created by the pro-competitive reforms.

Section 1 outlines how competition can be used as a policy tool in health care. Section 2 presents the precise form of the reforms undertaken in the United Kingdom and England. Section 3 presents the evidence that the UK provides, focusing primarily on the evidence drawn from large scale studies employing a quantitative approach. Section 4 lists the limitations of these studies and provides reflections on the lessons that can be drawn for policy makers from the English experience.

\section{Competition in health care}

\subsection{The nature of competition}

Competition can be used in both health care finance (i.e. supply) and delivery. Competition on the finance side is essentially the use of competition between providers of insurance for either corporate or individual business. Conversely, 
competition on the delivery side is the use of competition between suppliers of health care, where these may be either primary, secondary and/or tertiary care providers.

Competition between firms to supply insurance or health services may be accompanied by consumer choice, but the two are not equivalent. For competition to exist on the insurer side of a health care market, consumers (or their employers) must have a choice of options provided by more than one insurer. However, competition on the delivery side may involve direct user choice, but it may also not. In many cases in which competition between suppliers of health care has been introduced, a third party may make decisions for patients as to where they access care. In systems in which patients are covered by insurance, the insurers may offer contracts which restrict the set of health care suppliers that the insured individual may use. An example of an insurance model in which choice is very limited at point of demand is the health maintenance organisation model, which limits the physicians and hospitals that patients can select at point of care use. Where competition between suppliers of health care has been introduced into tax financed systems, often the choice of hospital and tertiary suppliers of health care is made by primary care physicians, not by the patient themselves, and in addition the patients may have limited choice of primary care physicians.

The United States has competition (and patient choice) on both sides of the market. Insurers compete for corporate and individual buyers and negotiate with competing suppliers to provide health care. Contracts on both sides are often very complex and one of the aims of the Affordable Care Act of 2010 (often known as ObamaCare) was to promote competition on the insurance side by providing consumers, through insurance exchanges, with less complex insurance contracts.

In Europe, pro-competitive reforms in the finance of health care (i.e. on the insurance side) have taken place in those health care systems where finance is provided by means of social insurance. These systems traditionally have had consumer choice of provider at the point of use. In recent years, many of these countries have faced strong cost containment issues. In response, Germany, and the Netherlands in particular, have sought to introduce choice on the financing side, in the shape of promoting competition between insurance funds. Switzerland and, to a limited extent, France have followed a similar path (Costa-Font and Zigante, 2012). Universality of coverage is maintained through continued compulsory insurance.

In contrast, in health care systems where finance is provided through taxation (e.g. United Kingdom, the Nordic countries, Spain, Portugal and Italy), there has been traditionally little choice of provider offered to consumers. These countries have reformed by promoting increasing levels of choice for consumers by separating the finance and delivery of health care and allowing and encouraging competition between suppliers, either of hospital-based services and/or community-based services, whilst maintaining universal coverage through taxation. The arrangements are sometimes referred to as 'quasi-markets' (Le Grand and Bartlett, 1993).

Early reformers were the United Kingdom and Sweden, where choice reforms have been a core point of debate since the early 1990s (Fotaki, 2007). Several of 
the Nordic countries have subsequently introduced similar reforms. In these reforms, universality of coverage remains (funded through taxation), but mechanisms are introduced to encourage providers of care to compete with each other to provide health care for local populations. The welfare discourse in Spain and Italy has been less focused on individual choice, but on territorial politics, which in turn encompasses varying degrees of provider choice (Durán et al., 2006; Costa-Font and Zigante, 2012). Providers may be public but can also be privatefor example in the Spanish regional state of Catalonia where the bulk of providers are private, and in the United Kingdom where private entry has been encouraged. ${ }^{1}$

While the precise mechanisms vary across countries, reforms aimed at encouraging competition in supply include three components: first, decentralisation of decision making (perhaps from national to local level, or from administrative bodies to the suppliers of care); second, the promotion of competition between suppliers (e.g. by making public providers into free-standing organisations with harder budget constraints); and third, changes in payments/incentives for suppliers of care (e.g. the introduction of prospective payment systems that pay suppliers a fixed-fee per type of treatment ex-ante).

The rest of the paper will focus on the effect of these reforms intended to bring about change by competition in supply, as it is this model that is pertinent to the UK case. However, before doing this, I briefly review the theoretical support for competition on the supply side and the evidence on competition in supply from the market in which this has been most extensive, the United States.

\subsection{Theoretical support for pro-competitive reforms in supply}

While the political appeal of these type of reforms can be large, the theoretical support for competition in supply is actually more limited. Gaynor and Town (2012) provide an in-depth review of the theoretical literature. In the past, many of the models used to examine competition between suppliers of health care were not very specific to the health care sector, though there is now a growing body of models which incorporate features such as budget constrained buyers and semialtruistic suppliers that present a more realistic depiction (e.g. Brekke et al., 2015).

The bottom line is that price regulation is key. Most theoretical models indicate that when prices are regulated (i.e. set by an outside body), competition generally raises quality; however, quality could be either too high or too low when prices are not regulated. The intuition behind these results is simple. If price is exogenously set, then the only dimensions on which sellers can compete for contracts to supply care to insurers or directly to health care users is quality. Thus, quality (or at least that which is measured) will in turn rise. This is similar to simple models of public school competition where parents do not pay fees (e.g. Hoxby, 2000). Where prices are not exogenous, if the buyers of health care (the insurers or the consumers) are very price sensitive, sellers of care have an incentive to skimp on (unmeasured) quality in order

1 Costa-Font and Ziganes (2012) and Freeman (1998) provide discussions of the drivers of these reforms. 
to win contracts. But if buyers are not price sensitive (e.g. in cases where consumers have generous insurance coverage), quality again becomes an important driver of choice and a key factor on which sellers will compete (or at least on those aspects of quality that buyers care about and can be measured).

\subsection{Evidence on competition in supply from the United States}

Much of the evidence on the impact of competition between suppliers comes from the United States, as competition in supply is, and has been for many years, a key component of the health care system.

The dominant approach until the last few years has been to adopt what is called a structure-conduct-performance (SCP) approach. In this approach, researchers construct measures of market concentration (usually a form of the HerfindahlHirschmann Index, which is used to measure market concentration in many industry contexts) and regress it on the variable of interest (e.g. prices or quality or quantity) controlling for observable confounding variables. This type of reduced form approach allows researchers to be somewhat agnostic about the underlying theoretical model, thereby enabling the data to speak directly to the relationships between the variables of interest. However, one problem with the SCP approach is that market concentration, no matter how it is measured, may be correlated with unobserved demand and strategic factors, creating endogeneity bias. Thus, much of the research has been concerned to overcome this problem.

The seminal paper in this area is Kessler and McClellan (2000), which examined the impact of competition on quality in the US Medicare market. This paper was followed by a relatively large set of studies employing a similar approach. The evidence from these US market level studies broadly supports the theoretical predictions: where prices are regulated, competition increases quality, but the effects are less clear where prices are market determined. In addition, the impact of competition may differ according to the nature of the buyer side of the market. A recent and authoritative review is provided in Gaynor and Town (2012).

Policy innovation in the use of competition, such as that introduced in the United Kingdom and other European countries, provides a good opportunity to examine the impact of policies to promote competition. In cases where competition is introduced exogenously by policy, it is possible to rule out reverse causality in the relationship between measures of performance of suppliers (be that quality or cost) and market structure. The United Kingdom has been a leader in the use of such policies and also has relatively good data, so provides a good test bed for examining the impact of these policies.

\section{The UK reforms}

The United Kingdom has experienced two waves of pro-competitive reforms in the provision of health care. These have sought to introduce competition in the 
hospital sector and in the provision of community services other than family doctor services (e.g. services for persons with mental health problems). There have been no systematic reforms to date to allow greater choice of family doctor by users, though in an attempt to make this more of an informed choice, the government has made increasing amounts of information available (at practice, rather than individual family doctor, level) on the performance of family practices. This has been enabled by the provision of greater information on the performance on all types of health care providers in England through a government run web site known as NHS Choices, which has provided comparable data on family doctors from around 2010 onwards. $^{2}$ The focus of the present review is on reforms to hospital care. ${ }^{3}$

The first set of pro-competitive reforms took place under the Conservative administration of the 1990s. They established a 'provider-purchaser split' between buyers and sellers of (hospital based) health care. Created from administrative bodies that previously received central government funding to run local hospitals, the buying and selling sides were formally separated. Buyers were given the responsibility (and budgets) for buying care for all people living within their geographic area. Sellers were public hospitals who were to earn their income by competing for contracts with the buyers. These contracts were predicated on prices and volume of services provided. Quality, except for the dimension of waiting times, was not generally a feature of these contracts.

The competition for contracts was initially abolished by the incoming Labour administration in 1997 with a policy of return to 'co-operation' between providers and purchasers at the local level. However, as concerns over lack of productivity growth mounted during the early 2000s, competition was re-introduced in the mid-2000s (Propper, 2012). The reforms of the 2000s were of a similar nature to those of the 1990s with some important institutional differences (see also Cooper et al., 2011; Gaynor et al., 2013).

First, the reforms were initially introduced in all of the United Kingdom, but following the devolution of powers for health care to the four countries of the United Kingdom, they were rejected in Scotland, Wales and Northern Ireland. Second, the reforms included patient choice as a mechanism for promoting competition. Initially patients were to be offered the choice of up to five hospitals where they could have their first consultation with a specialist (specialists are hospital employees in the United Kingdom). From 2008 onwards, patient choice was expanded to any hospital in England. Third, data on quality and other attributes of care were much more available than in the first wave of reforms when there was no directly comparable data on quality at hospital level. These data were made available to both General Practitioners (family doctors) who act as the

2 See http://www.nhs.uk/pages/home.aspx (accessed 25 March 2017).

3 Reforms to community health care services have been less studied using quantitative approaches, partly because access to data is more difficult than for hospital or family doctor providers. 
gatekeepers to secondary care in the United Kingdom and also directly to the users of care. ${ }^{4}$ Fourth, prices for elective care were set centrally using a prospective payment system similar to the US DRG system. This was intended to cover around $65 \%$ of hospital activity. Fifth, the incentives for sellers to compete were sharpened through two further reforms. The first was the creation of the Foundation Trust (FT) programme. This allowed hospitals that were deemed by the regulator to be 'better run' greater autonomy of action, including retention of surpluses. Better run status was defined primarily in terms of financial propriety and a reduction in waiting times. All hospitals could apply for FT status, and thus, the programme essentially gave all hospitals (not just FTs) an incentive to be financially viable and, possibly, to increase quality or at least not increase waiting times. The second route involved the government subsidisation of private sector providers to supply elective treatments for which there were long waiting lists. While this began slowly in the mid-2000s, private provision of NHS-funded elective care has grown rapidly since. ${ }^{5}$

\section{The impact of the reforms}

I begin by briefly reviewing the evidence from the first wave of pro-competitive reforms and then focus in on evidence from the second.

\subsection{The 1990s internal market}

The evidence from the 1990s reforms is relatively limited. What evidence there is suggests the following. First, costs may have fallen more in competitive areas (Propper and Soderlund, 1998). Second, buyers of health care who were primary care providers (GP fund holders) seemed to be able to extract better deals from hospitals than the larger purchasers responsible for whole populations of patients in their area and for purchasing emergency, as well as elective care. This was perhaps because they had stronger financial incentives, in that any gains from purchasing could be retained to put into their practices, whereas the larger purchasers had to break even every year. The larger purchasers were also concerned about the viability of local services if they moved services at the margin, whereas the fund holders were less concerned with this issue as they had no remit for provision of all secondary care services (Le Grand et al., 1998). Third, hospitals facing more competition focused on bringing down waiting times but at the expense of unobserved quality (Propper et al., 2004, 2008). The findings that both waiting times but also unobserved quality fell, while uncomfortable for proponents of competition, fits with the predictions from simple models of competition with imperfect information that

4 The government implemented a web site known as NHS Choices. At its inception in the mid-2006 it contained data on waiting times and some simple measures of clinical quality. Since that date the government has steadily added information covering a wide range of service providers on aspects of care including clinical quality. See http://www.nhs.uk/pages/home.aspx (accessed 15 June 2017).

5 For example, in fiscal year 2010/2011, private hospital care accounted for around $17 \%$ of inpatient hip replacements (Kelly and Tetlow, 2012). 
show that as competition increases, sellers will focus on those aspects of care for which demand is more elastic (Gaynor and Town, 2012). As buyers of care during this period were interested primarily in increasing volume and reducing waiting times while quality of care was not made public, it is not surprising that sellers engaging in competition focused on bringing down waiting times at the expense of unmeasured quality. Fourth, despite the political fears of two-tier services, there is little evidence that patients whose secondary elective care was purchased by GP fund holders received more care than those patients covered by the larger health authorities (Cookson et al., 2012).

The evaluation of these reforms was hampered by a lack of data. So, for example, the most robust study of the impact of competition, which exploits prereform variation in hospital density, examined only waiting times and quality as measured within hospital mortality following admissions for heart attacks (Propper et al., 2008). Whereas this measure has been used extensively in the economics literature as a measure of hospital quality, death rates, although important, are only one aspect of quality and there are issues concerning their reliability when volumes of admissions are small, and thus, the measures are noisy from year to year. In addition, studies were not able to get within the 'black box' of what exactly hospital managers and buyers were doing to bring about gains (and losses) from competition. But the evaluations were also hampered by the short-lived nature of the reforms, which were only implemented in 1991 and ended in 1997. Even during the reform period, driven by fears of the emergence of a two-tier system and perhaps a more general concern by central government to limit variation in the NHS, the effect of the reforms was muted and the freedom of buyers and sellers was curtailed (Le Grand et al., 1998).

\subsection{The pro-competitive reforms of the $2000 \mathrm{~s}$}

The evidence base for these reforms is considerably larger than for the earlier reforms and is still growing. There is also a related literature on the use of consumer choice in health care which examines whether increasing consumer choice in heavily regulated systems leads to improvements in the quality or other attributes of care. This mainly examines mandated changes to choice of family doctor care in the Nordic tax financed systems (see e.g. Miani et al., 2013). This literature is not reviewed here except where this is pertinent to asking whether the pro-competition reforms changed behaviours in the United Kingdom.

\subsubsection{The impact on choice and market structure}

The intention of the reforms was to promote competition through the use of greater patient choice. Therefore, the first question to be asked is whether this occurred. In terms of patient knowledge of choice, around $50 \%$ of patients recalled being offered choice of hospital by their family doctor (who act as gatekeepers for hospital care in the United Kingdom) within two years of the reform 
(Propper, 2012). On the other hand, there was a view during the first two years following the reforms from some family doctors that choice was not needed or wanted by their patients (Dixon et al., 2010).

Whilst this may be true, there is a growing body of evidence from large scale studies using administrative data that treatment location has changed (e.g. Kelly and Tetlow, 2012 who study the role of private providers in the provision of elective care). It should be noted that patients choose on the basis of quality, as well as distance in England, when they select a health care provider. This includes choice of family doctors (Santos et al., 2017), provider of elective hip replacement surgery (Kelly and Stoye, 2015; Gutacker et al., 2016), and of open heart surgery. In some cases, this will reflect just the choices of patients, as of family doctors. In other cases, these choices will be influenced by an (informed) agent. So, in the case of choice of where elective surgery is taken, some of the information is provided directly to patients by a national web site (NHS Choices ${ }^{6}$ ); however, patients will also be influenced by the information provided from, and potentially by the choices of, their family doctors, made on their behalf. And in some cases the change in behaviours in response to the extension of choice probably came through the action of the patients' doctors rather than the patients themselves. For example, in the case of cardiac surgery examined in Gaynor et al. (2016), informed cardiologists would probably have played a large role in referring patients to cardiac surgeons.

To date, there have been no published studies for England which attempt to separate out the role of doctor and patient in making these choices. Yet, this is important in understanding exactly how a policy of increasing information to consumers has brought about the changes seen in patient behaviour.

There is also evidence that these changes in patient behaviour had a differential impact on health care providers. Hospitals with better clinical care pre-reform appear to have attracted more patients post-reform. Further, these patients were more likely to by-pass their local hospital (the default provider under the nochoice regime) post-reform (Gaynor et al., 2013; Gutacker et al., 2016). There is also evidence that hospital market structure became less concentrated. Put another way, hospitals faced greater potential competition after the reforms (Gaynor et al., 2013). Interestingly, those hospitals which experienced most change in potential competition were not those located in the large cities, as these had previously been exposed to greater potential competition by virtue of greater population density. Instead, those hospitals which experienced greatest change in competition were located around the large cities, particularly around the Greater London area (Gaynor et al., 2013). So there is evidence that, at least close to the initial implementation of the reforms in the mid-2000s, the reforms led to changes in patient flows and market structure.

Given that these changes have been documented, the next question is whether changes in outcomes have come about as a result.

6 http://www.nhs.uk/pages/home.aspx (accessed 15 June 2017). 


\subsubsection{The impact on activity, quality, access and inequality}

The evidence on the impact of the reforms on outcomes is still relatively small but is growing. The extant research studies that employ robust methodology tend to examine only a limited number of outcomes. In markets where prices are fixed (as in the second wave of reforms in the United Kingdom or in the US Medicare market), these are generally specific measures of clinical quality. A popular choice of clinical outcome is deaths following emergency heart attack admissions (AMI). This has been widely used in the literature which seeks to assess the effect of market structure or market reforms on the behaviour of health care providers. For example, it was used as a measure of quality in the seminal paper by Kessler and McClellan (2000), which examined the relationship between market structure and quality in the United States and recently was used to examine health care market dynamics (Chandra et al., 2016), again in the United States. It is not argued in these papers that AMI deaths are the only measure of quality, but instead that AMI death rates are relatively reliable and less open to manipulation than other measures of quality. More recently, as data availability has increased, researchers have used a wider range of quality measures, driven in part by the low correlation between some commonly used measures. 7

Measures of activity are easier to access. Studies of access and inequality also tend to focus on a relatively small number of types of treatment, most notably elective care for joint replacement.

In terms of the empirical approach to assessing the effect of changes in market structure, earlier studies adopted a 'reduced form' approach, which examines the impact of exposure to greater competition pre- and post-policy intervention. This approach exploits natural variation in the exposure to competition determined by the pre-existing geographical location of hospitals to compare outcomes pre- and post-policy for providers who were more or less exposed to the policy. More recently, researchers have estimated more structural models which estimate the effect of the reforms on patient choices and then uses this to examine the impact of estimated changes in patient choice on the behaviour of providers.

Farrar et al. (2009) sought to isolate the impact of case-based payments on activity using a reduced form approach which compared providers who piloted the case-based payment system with those who did not (including in the latter group, hospitals in Scotland). This allowed them to isolate the effect of case-based payments from choice, as the choice policy was not operating in the three years (fiscal years 2003-2005) that they examine. They found that length of stay fell more quickly and the proportion of day cases increased more quickly where payment by results was implemented, suggesting a reduction in the unit costs of care associated with payment by results. Some evidence of an association between

7 Correlations amongst measures of emergency quality, amongst measures of elective quality, and between emergency and elective quality are low in English data. Gutacker et al. (2015) examined 16 quality indicators across English hospitals and found correlations ranging between $-16 \%$ and $32 \%$. 
the introduction of payment by results and growth in acute hospital activity was also found: this is a relatively common response to payment for activity.

Later studies examine the impact of the full set of reforms, which included patient choice and the entry by private providers. Using a reduced form approach, Cooper et al. (2011) and Gaynor et al. (2013) show that mortality rates after admission for emergency heart attacks (AMI) fell and fell by more in hospitals operating in markets which were more exposed to competition. Feng et al. (2015) found no effect on patient reported outcomes for hip or knee replacement surgery while Moscelli et al. (2016) found that quality, as measured by the probability of readmission, also fell.

More structural approaches, which estimate the relationship between patient demand and mortality (as a measure of quality) have shown, in some studies, that patients who were given greater choice after the reforms have had quality improvements. Gaynor et al. (2016) find that patients whose choice sets increase after the reforms have lower mortality and that hospitals which experienced more competitive pressure raised the quality of their heart surgery. On the other hand, Moscelli et al. (2016) find no effect on mortality for a similar set of patients. Gutacker et al. (2016) found that hospital elasticity of demand for hip replacement surgery with respect to quality rose. In other words, patients (or their family doctors making decisions on their behalf) became more sensitive to quality after they were allowed more choice.

There is less evidence on the impact on productivity, partly because good summary measures of hospital productivity are hard to construct and partly because the literature on hospital production in the United Kingdom has not tended to consider market structure as a determinant or shifter of productivity. One proxy for productivity is length of stay. Reducing length of stay is seen as a measure of increased productivity in most health care systems and has been an important target for the UK government. Both Cooper et al. (2011) and Gaynor et al. (2013), in reduced form analyses, show that length of stay fell while total hospital expenditure remained constant, suggesting that hospital productivity increased.

Opponents of choice-based reforms in the United Kingdom have argued that choice favours more affluent individuals. However, whilst studies of particular conditions suggest that access to some forms of care is better for individuals of higher socio-economic status (Cookson et al., 2016), the impact of the procompetitive reforms with their associated lifting of restrictions on choice does not appear to have worsened socio-economic inequalities in access to care. Moscelli et al. (2015) examine waiting times for cardiac surgery and find that over the period covered by the choice reforms, waiting times fell quite substantially and differential access also decreased. In 2002 patients in need of coronary artery bypass graft surgery in the least deprived quintile waited $35 \%$ less compared to the most deprived ones. The gradient gradually falls to $10 \%$ in 2010 following the general reductions in waiting times at the system level and the gradient is not 
substantially altered once patients' choice over hospital or treatment is taken into account. Cookson et al. $(2012,2013)$ examine the relationship at small area level between competition amongst providers and access to hip replacement surgery and find that the reforms did not have a negative effect on access to care of individuals living in lower socio-economic status communities.

\subsubsection{The effect of hospital consolidation}

Whilst the UK government pursued a policy of competition in the early to mid1990s and incentivised choice and competition from the mid-2000s, in the period between 1997 and 2005, the UK government undertook a wave of consolidation in English hospitals. This lead to a fall in the median number of hospitals in a local market from 7 to 5 . Because hospital closure is politically unpopular in the United Kingdom (as in other countries), closure is not random. Instead, hospitals in politically marginal electoral areas tend to close less (Bloom et al., 2015). This means that market structure is potentially exogenous, even in a cross-sectional setting, provided there has been a period of consolidations. This idea has been used in two studies, one of which examines the effect of mergers on hospital performance. Gaynor et al. (2012) examined the impact of these consolidations up to eight years later (the median time was four years later). They found that hospital consolidation had no positive impact on labour productivity, waiting times or clinical outcomes and in fact, financial performance fell, rather than rose, post-consolidation. The only benefit from merger activity was to reduce capacity in the secondary care sector. This suggests three things: first, that consolidation in this industry will not bring about rapid short-term gains; second, as in other industries, the benefits of mergers are overstated ex-ante; and third, because the merging hospitals face less potential competition than they did pre-mergers, a decrease in potential competition does not improve performance.

\subsubsection{How the reforms brought about changes}

While there is a body of evidence that suggests that the pro-competitive reforms brought some gains in quality and potentially productivity, there has been considerably less study of how these benefits arose. One exception is a study that examined the relationship between competition, the quality of management practices and hospital outcomes in the United Kingdom. Higher quality management has been shown in other settings to improve firm productivity (Bloom and Van Reenen, 2007; Bloom et al., 2012). Bloom et al. (2015) use a measure of management quality that has been used across industries and countries (Bloom et al., 2012) to examine whether the quality of NHS hospital management is affected by competition. They find support for this. NHS hospitals with better management practices have better clinical and financial performance, lower waiting times, higher staff satisfaction and receive higher regulator ratings. Further, by exploiting the fact the hospitals located near marginal constituencies face more 
competition, they find that exposure to greater competition from other hospitals located nearby leads to better management practices. Thus, one possible route by which hospitals improved outcomes in response to the fall in market concentration post the pro-competitive reforms of the 2000s was by implementing better management practices. However, this has not been studied directly.

\section{Discussion}

The survey above suggests that the pro-competitive policies undertaken by the UK government and implemented in England have broadly had positive effects. To summarise, patients and hospitals have responded in a manner that suggests patients care about quality and hospitals, in turn, respond to demand. Better hospitals have attracted more patients, the quality of some services has risen, there do not appear to have been large equity issues, and policies that pursue the alternative tack of consolidation have not brought benefits in the medium term. Hospital consolidation, on the other hand, has not been documented to show large gains. It should be acknowledged that the evidence is often treatment specific and only a relatively narrow set of treatments have been examined, many of which are elective services. While these account for a relatively large proportion of hospital services, they are not the only outputs of hospitals.

More generally, although not without some problems, the policy was relatively well crafted to address problems in health care service markets. Learning from earlier changes of the 1990s, the funding model was changed to a prospective casebased funding model, meaning that competition, if it occurred, would not be on price. Web-based resources were created to support patient choice; GPs were required to provide five options to their patients; and GPs' role as potential advisor to patients was built into the policy approach. Private providers were encouraged to provide extra capacity. So importantly, the government did not simply decree that patients would be given choice. Instead, it undertook real effort to create institutional elements in the 'market' to support the policy direction.

These specific components, whilst acknowledged as important, have not been subject to systematic scrutiny to unpick the relative contribution of each component. There is a growing body of evidence which examines parts of the picture. For example, there is a growing body of research which shows that patients do choose on the basis of (some aspects of) clinical quality as evidenced by those studies cited above for England, and a broader set of studies for other European countries (e.g. Gaynor et al., 2016 for England, Miani et al., 2013). There is also work on the impact of entry of new providers (e.g. Kelly and Stoye, 2015). And Farrar et al. (2009) provide evidence on the effect of case-based payment.

But the research driven by administrative data to date has tended to be, with a few exceptions, focused more on documenting what has happened, rather than undertaking detailed assessments of the impact of each component of the reform package. And there are some gaps: there is little work on the effect of competition 
on productivity, which contrasts with the large body of work undertaken to develop robust measures of hospital productivity in the United Kingdom (e.g. Bojke et al., 2017) and elsewhere. ${ }^{8}$ Further, the gains have not been set against the broader costs of introducing these changes. ${ }^{9}$ In general, we cannot yet unpack the separate components of the reform package: for example, we cannot say how much was due to increased choice by patients; how much was due to the use of case-base payment systems; how much was due to the greater entry of private providers; or how much was due to the freedoms given to well performing NHS hospitals. This remains to be done.

Nevertheless, in the context of the highly regulated European health care systems, we know considerably more about the effect of these changes than in other European countries that have sought to extend choice and harness competitive forces to improve productivity. The United Kingdom has not been alone in using competition as a means of improving health care provision in the European context. The Nordic countries, the Netherlands, France, Germany, Portugal and Spain have all implemented larger (as in the case of the Netherlands and several of the Nordic countries) or smaller (e.g. France) changes to foster competition (Siciliani et al., 2017). In contrast with the United Kingdom, there has been little evaluation of the impact of these reforms on outcomes or clinical quality in hospitals primarily due to a lack of data. What is clear is that on the supply side, one consequence of the reforms to promote competition has been increased merger and consolidation in the market. This is particularly the case on the provider side in the Netherlands and Germany and on the insurer side, as well, in the Netherlands. This might be the appropriate response to the presence of too many small hospitals which are not able to operate at a scale sufficient to bring about gains in clinical quality in addition to the cost of bargaining between insurers and hospitals. But it may also reflect attempts by providers, on the part both the hospital and the insurers, to gain market power. ${ }^{10}$ These results indicate the importance of market regulation to ensure that the natural tendency of providers to avoid direct competition does not negate the impact of reforms to promote competition.

It is also clear that equity concerns limit the strength of incentives that can be used. Thus, in the Netherlands, concerns over incentives for insurers to cream-skim when competition is introduced, have led to a high level of government regulation of competition between insurers. This includes government reimbursement of insurers to compensate for differential risk across patients, as well as mandatory open

8 For a recent review of measurement of productivity, see Sheiner and Malinovskaya https://www. brookings.edu/wp-content/uploads/2016/08/hp-lit-review_final.pdf

9 There is no single over-arching assessment of the impact of these set of reforms, partly because they have effects on many aspects of production, but also because it would be difficult to construct a relevant counterfactual. All policy change has costs, but these typically are not counted (because they are difficult to assess), either for the reforms or the potential counterfactuals.

10 In cases where there are small numbers of insurers and providers in the market, the predictions of the effect of competition on outcomes and welfare can be complex (e.g. Gaynor et al., 2015). 
enrolment periods (Van de Ven and Schut, 2008). However, these provisions give competing insurers relatively small margins on which to compete.

In the UK as well, in response to (possibly unfounded) equity concerns (e.g. Cookson et al., 2016), there has been political push-back against the concepts of choice and competition. The devolved administrations of Scotland, Northern Ireland and Wales rejected the pro-competitive model when it was re-introduced by the Blair administration in the mid-2000s. This might have been a sensible reaction to the smaller size of their hospital sectors and a lower destiny population distribution, but it also reflected a belief that market-based reforms were not desirable. And in England, in the more straightened fiscal environment following the 'Great Recession', the policy making community has tended to see competition as less important than other changes (Ham, 2014) and there continue to be (sometimes rather polemically expressed) concerns that competition equates to privatisation. $^{11}$

These views aside, competition is a means to an end, not an end in itself, and can operate alongside other reforms. In an era in which demand pressures on health care are only set to rise, the exposure of suppliers to both greater competition and patient choice are likely to remain part of most government's attempts to improve productivity in the health care sector. The evidence presented here suggests that they have scope to improve health care delivery.

\section{Acknowledgements}

The author thank two anonymous referees whose insightful comments considerably improved the paper. Financial support was provided by the ESRC under the Professorial Fellowship ES/J023108/1. All error remain my own.

\section{References}

Aghion, P., N. Bloom, R. Blundell, R. Griffith and P. Howitt (2005), 'The relationship between growth and competition', Quarterly Journal of Economics, 120: 701-728.

Bloom, N and J. Van Reenen (2007), 'Measuring and explaining management practices across firms and countries', The Quarterly Journal of Economics, 122(4): 1351-1408.

Bloom, N., C. Genakos, R. Sadun and J. V. Reenen (2012), 'Management practices across firms and countries', Academy of Management Perspectives, 26(1): 12-33.

Bloom, N., C. Propper, S. Seiler and J. Van Reenen (2015), “"The impact of competition on management quality: evidence from public hospitals"', Review of Economic Studies, 82: 457-489.

Bojke, C., A. Castelli, K. Grašič and A. D. Street (2017), 'Productivity growth in the English National Health Service from 1998/1999 to 2013/2014', Health Economics, 26(5): 547-565.

11 An example of the type of discussion is http://www.allysonpollock.com/?p=2270 (accessed 25 March 2017). 
Brekke, K, L. Siciliani and O. R. Straume (2015), 'Hospital competition with soft budgets', Scandinavian Journal of Economics, 117: 1019-1048.

Chandra, A., A. Finkelstein, A. Sacarny and C. Syverson (2016), 'Health care exceptionalism? Performance and allocation in the US health care sector', American Economic Review, 106(8): 2110-2144.

Cookson, R., M. Laudicella and P. L. Donni (2012), 'Measuring change in health care equity using small-area administrative data - evidence from the English NHS 2001-2008', Social Science and Medicine, 75(8): 1514-1522.

Cookson, R., M. Laudicella and P. Li Donni (2013), 'Does hospital competition harm equity? Evidence from the English National Health Service', Journal of Health Economics, 32: 410-422.

Cookson, R, C. Propper, M. Asaria and R. Raine (2016), 'Socioeconomic inequalities in health care in England', Fiscal Studies, 37: 371-403.

Cooper, Z., S. Gibbons, S. Jones and A. McGuire (2011), 'Does hospital competition save lives? Evidence from the English Patient Choice Reforms', The Economic Journal, 121(August): 228-260.

Costa-Font, J. and V. Zigante (2012), 'Are Health Care "Choice - and - Competition" Reforms really Efficiency Driven?’, LSE Health Working Paper 26/2012. http://www.lse.ac.uk/ LSEHealthAndSocialCare/pdf/LSEHWP26.pdf [21 March 2017].

Dixon, A., J. Appleby, R. Robertson, P. Burge, N. Devlin and H. Magee (2010), How Patients Choose and How Providers Respond, London: Kings Fund.

Durán, A., J. Lara and M. van Waveren (2006), 'Spain: health system review', Health Systems in Transition, 8(4): 1-208.

Farrar, S., D. Yi, M. Sutton, M. Chalkley, J. Sussex and T. Scott (2009), 'Has payment by results affected the way that English hospitals provide care? Difference-in-differences analysis', BMJ, 339: b3047.

Feng, Y., M. Pistollato, A. Charlesworth, N. Devlin, C. Propper and J. Sussex (2015), 'Association between market concentration of hospitals and patient health gain following hip replacement surgery', Journal of Health Services Research of Policy, 20: 11-17.

Fotaki, M. (2007), 'Patient choice in healthcare in England and Sweden: from Quasi-market and back to Market? A comparative analysis of failure in unlearning', Public Administration, 85(4): 1059-1075.

Freeman, R. (1998), 'Competition in context: the politics of health care reform in Europe', International Journal for Quality in Health Care, 10(5): 395-401.

Gaynor, M. and R. J. Town (2012), 'Competition in Health Care Markets', in M. V. Pauly, T. G. McGuire and P. P. Barros (eds), Handbook of Health Economics, Volume 2, Amsterdam: Elsevier B.V, 499-637.

Gaynor, M., M. Laudicella and C. Propper (2012), 'Can governments do it better? Merger mania and hospital outcomes in the English NHS', Journal of Health Economics, 31: 528-543.

Gaynor, M., R. Moreno-Serra and C. Propper (2013), 'Death by market power: reform, competition, and patient outcomes in the National Health Service', American Economic Journal-Economic Policy, 5: 134-166.

Gaynor, M., K. Ho and R. J. Town (2015), 'The industrial organization of health care markets', Journal of Economic Literature, 53(2): 235-284.

Gaynor, M., C. Propper and S. Seiler (2016), 'Free to choose? Reform, choice, and consideration sets in the English National Health Service', American Economic Review, 106(11): 3521-3557. 
Gowrisankaran, G., A. Nevo and B. Town (2015), 'Mergers when prices are negotiated: evidence from the Hospital Industry', American Economic Review, 105(1): 172-203.

Gutacker, N., L. Siciliani, G. Moscelli and H. Gravelle (2015), 'Do patients choose hospitals that improve their health', University of York, Centre for Health Economics WP 111.

Gutacker, N., L. Siciliani, G. Moscelli and H. Gravelle (2016), 'Choice of hospital: which type of quality matters?', Journal of Health Economics, 50: 230-246.

Ham, C. (2014), Reforming the NHS From Within: Beyond Hierarchy, Inspection and Markets, London: Kings Fund.

Hoxby, C. M. (2000), 'Does competition among public schools benefit students and taxpayers?', American Economic Review, 90(5): 1209-1238.

Kelly, E. and G. Tetlow (2012), 'Choosing the place of care: the effect of choice on treatment location in England, 2003-11', Institute for Fiscal Studies and Nuffield Trust Report https://www.nuffieldtrust.org.uk/files/2017-01/choosing-place-of-care-web-final.pdf [19 June 2017].

Kelly, E. and G. Stoye (2015), 'New joints: private providers and rising demand in the English National Health Service', IFS Working Paper (W16/15) https://www.ifs.org.uk/publications/ 8451 [21 March 2017].

Kessler, D. and M. McClellan (2000), 'Is hospital competition socially wasteful?', The Quarterly Journal of Economics, 115: 577-615.

Le Grand, J. (2006), Motivation, Agency, and Public Policy: Of Knights and Knaves, Pawns and Queens, Oxford: OUP.

Le Grand, J. and W. Bartlett (1993), Quasi-Markets and Social Policy, London: MacMillan.

Le Grand, J., N. Mays and J. Mulligan (eds) (1998), Learning From the Internal Market: A Review of the Evidence, London: Kings Fund.

Miani, C., E. Pitchforth and E. Nolte (2013), 'Choice of primary care provider: a review of experiences in three countries', London School of Hygiene and Tropical Medicine, Policy Innovation Research Unit, London.

Moscelli, G., G. Moscelli, L. Siciliani, N. Gutacker and R. Cookson (2015), 'Socioeconomic Inequality of Access to Healthcare: Does Patients' Choice Explain the Gradient? Evidence from the English NHS', Centre for Health Economics University of York CHE Research paper 112, York.

Moscelli, G., H. Gravelle and L. Siciliani (2016), 'Market Structure, Patient Choice and Hospital Quality for Elective Patients', Centre for Health Economics University of York CHE Research paper 139, York.

Propper, C. (2012), 'Competition, incentives and the English NHS', Health Economics, 21: 33-40.

Propper, C. and N. Soderlund (1998), 'Competition in the NHS internal market: an overview of its effects on hospital prices and costs', Health Economics, 7: 187-197.

Propper, C., S. Burgess and K. Green (2004), 'Does competition between hospitals improve the quality of care? Hospital death rates and the NHS internal market', Journal of Public Economics, 88(7-8): 1247-1272.

Propper, C., S. Burgess and D. Gossage (2008), 'Competition and quality: evidence from the NHS internal market 1991-1996', Economic Journal, 118(1): 138-170.

Santos, R., H. Gravelle and C. Propper (2017), 'Does quality affect patients' choice of doctor? Evidence from England', The Economic Journal, 127: 445-494.

Siciliani, L., M. Chalkley and H. Gravelle (2017), 'Policies towards hospital and GP competition in five European countries', Health Policy, 121(2): 103-110.

Van de Ven, W. and F. Schut (2008), 'Universal mandatory health insurance in the Netherlands: a model for the United States?', Health Affairs, 27: 3771-3781. 